Article

\title{
New Species of the Genus Curvularia: C. tamilnaduensis and C. coimbatorensis from Fungal Keratitis Cases in South India
}

\author{
Noémi Kiss ${ }^{1}$, Mónika Homa ${ }^{1,2}$, Palanisamy Manikandan ${ }^{3,4} \oplus$, Arumugam Mythili ${ }^{5}$, \\ Krisztina Krizsán ${ }^{6}$, Rajaraman Revathi ${ }^{7}$, Mónika Varga ${ }^{1}$, Tamás Papp ${ }^{1,2} \mathbb{D}$, Csaba Vágvölgyi ${ }^{1} \mathbb{D}$, \\ László Kredics ${ }^{1, *}$ (i) and Sándor Kocsubé ${ }^{1, *}$ \\ 1 Department of Microbiology, Faculty of Science and Informatics, University of Szeged, 6726 Szeged, \\ Hungary; kissnoemi621@gmail.com (N.K.); homamoni@gmail.com (M.H.); \\ varga.j.monika@gmail.com (M.V.); pappt@bio.u-szeged.hu (T.P.); csaba@bio.u-szeged.hu (C.V.) \\ 2 MTA-SZTE “Lendület” Fungal Pathogenicity Mechanisms Research Group, 6726 Szeged, Hungary \\ 3 Department of Medical Laboratory Sciences, College of Applied Medical Sciences, Majmaah University, \\ Al Majmaah 11952, Saudi Arabia; manikandanpalanisamy@gmail.com \\ 4 Greenlink Analytical and Research Laboratory India Private Ltd., Coimbatore, Tamil Nadu 641014, India \\ 5 Department of Microbiology, Dr. G.R. Damodaran College of Science, Coimbatore, Tamil Nadu 641014, \\ India; mythilia1689@gmail.com \\ 6 Synthetic and Systems Biology Unit, Institute of Biochemistry, Biological Research Centre, \\ Hungarian Academy of Sciences, 6726 Szeged, Hungary; krizsank@gmail.com \\ 7 Aravind Eye Hospital and Postgraduate Institute of Ophthalmology, Coimbatore, Tamil Nadu 641014, India; \\ revathi@aravind.org \\ * Correspondence: kredics@bio.u-szeged.hu; (L.K.); shigsanyi@gmail.com; (S.K.)
}

Received: 6 December 2019; Accepted: 18 December 2019; Published: 20 December 2019

\begin{abstract}
Members of the genus Curvularia are melanin-producing dematiaceous fungi of increasing clinical importance as causal agents of both local and invasive infections. This study contributes to the taxonomical and clinical knowledge of this genus by describing two new Curvularia species based on isolates from corneal scrapings of South Indian fungal keratitis patients. The phylogeny of the genus was updated based on three phylogenetic markers: the internal transcribed spacer (ITS) region of the ribosomal RNA gene cluster as well as fragments of the glyceraldehyde-3-phosphate dehydrogenase $(g p d h)$ and translation elongation factor $1-\alpha(t e f 1 \alpha)$ genes. The maximum likelihood phylogenetic tree constructed from the alignment of the three concatenated loci revealed that the examined isolates are representing two new, yet undescribed, Curvularia species. Examination of colony and microscopic morphology revealed differences between the two species as well as between the new species and their close relatives. The new species were formally described as Curvularia tamilnaduensis N. Kiss \& S. Kocsubé sp. nov. and Curvularia coimbatorensis N. Kiss \& S. Kocsubé sp. nov. Antifungal susceptibility testing by the broth microdilution method of CLSI (Clinical \& Laboratory Standards Institute) revealed that the type strain of $C$. coimbatorensis is less susceptible to a series of antifungals than the $C$. tamilnaduensis strains.
\end{abstract}

Keywords: Curvularia; keratitis; taxonomy; antifungal susceptibility; Curvularia coimbatorensis; Curoularia tamilnaduensis

\section{Introduction}

The fungal genus Curvularia (Ascomycota, Pleosporales, Pleosporaceae) comprises of dematiaceous, melanin-producing molds with various lifestyles including saprophytism, plant endophytism [1], plant parasitism [2], and human pathogenicity [3]. 
The genus-level identification of Curvularia was performed traditionally by the examination of pigmentation, as well as the morphology of the septate conidia and hyphae [3]. The first sequence-based species-level identification attempts targeted the internal transcribed spacer (ITS) region of the ribosomal RNA gene cluster, which alone, however, proved inappropriate, either for the purposes of exact diagnosis [4] or for the phylogenetic resolution of the genus and the clarification of its relationship to the closely related genera Bipolaris, Cochliobolus, and Drechslera [3]. Multilocus sequence typing (MLST) involving fragments of the nuclear ribosomal large subunit RNA (LSU) as well as the glyceraldehyde-3-phosphate dehydrogenase ( $g p d h)$ and translation elongation factor 1- $\alpha(t e f 1 a)$ genes in addition to ITS had resulted in the recently accepted phylogenetic concept of the genus Curvularia [5], which was applied in more recent works [6-8]. Recently, the genus involves more than 100 described species, which can be divided into six clades (americana, eragrostidis, hominis, lunata, spicifera, and trifolii) according to Madrid et al. [7] based on MLST of four loci (ITS, LSU, gpdh, and the RNA polymerase II subunit $r p b 2$ ).

Krizsán et al. [3] reviewed the clinical importance of the genus Curvularia, and identified Curvularia australiensis, Curvularia geniculata, Curvularia hawaiiensis, Curvularia lunata, Curvularia pallescens, and Curvularia spicifera as the species most frequently isolated from clinical samples. Further members of the genus with confirmed clinical relevance include Curvularia americana, Curvularia chlamydospora, Curvularia hominis, Curvularia muehlenbeckiae, Curvularia pseudolunata [7], Curvularia brachyspora [9], Curvularia senegalensis [10,11], Curvularia clavata [12], Curvularia tuberculata [13], and Curvularia inaequalis [14-16]. A Curvularia infection in humans is designated as curvulariosis, a subtype of phaeohyphomycoses (i.e., fungal infections caused by dematiaceous fungi) [3]. The resulting diseases include deep and disseminated infections [3,17-19], infections complicating peritoneal dialysis $[14,20,21]$, respiratory infections including sinusitis and bronchopulmonary mycosis $[3,10,22]$, urinary tract infections [23], as well as localized infections affecting the skin, nail $[4,24,25]$, and the eye. Among eye infections, the involvement of Curvularia spp. is most frequent in keratitis-a suppurative, ulcerative disease of the cornea, but endophthalmitis and chronic dacryocystitis cases have also been reported [3,26].

In this study, we describe two new species of the genus Curvularia, the type strains of which were isolated from corneal scraping samples derived from South Indian patients diagnosed with fungal keratitis.

\section{Results}

\subsection{Strain Selection and Case Details}

About two thirds of the dematiaceous fungi isolated from corneal ulcers in the Aravind Eye Hospital, Coimbatore, Tamil Nadu, India belong to the genus Curvularia (unpublished data). The four strains involved in this study were selected retrospectively based on the inability of reliable species-level identification of some Curvularia isolates by ITS sequence analysis. Details available of the cases are presented in Table 1. All four patients were diagnosed with fungal corneal ulcer. The corneal scrapings from the ulcers were in all cases positive for fungal filaments in direct microscopy (both $10 \% \mathrm{KOH}$ and Gram staining). None of the cases had a history of contact lens wear. History of falling dust (2) and mud (1) into the eye was recorded as predisposing factors. Based on the typical clinical picture and the $\mathrm{KOH}$ report, topical antifungal therapy was started with natamycin ( $5 \%$ suspension) and econazole drops ( $2 \%$ ) every half an hour, along with homatropine ( $1 \%$ ) administered three times a day. Unfortunately, the patients were lost to follow up after one or two visits. 
Table 1. Case details of the fungal keratitis infections.

\begin{tabular}{|c|c|c|c|c|c|c|}
\hline Strain & Age & Sex & $\begin{array}{l}\text { Clinical } \\
\text { Diagnosis }\end{array}$ & $\begin{array}{l}\text { Corneal } \\
\text { Scraping }\end{array}$ & Therapy & Outcome \\
\hline SZMC 22225 & 80 & Male & $\begin{array}{l}\text { Fungal } \\
\text { corneal ulcer }\end{array}$ & 11 July 2012 & $\begin{array}{l}\text { NAT, ECZ, } \\
\text { HTR }\end{array}$ & $\begin{array}{l}\text { Lost to follow up } \\
\text { after two visits }\end{array}$ \\
\hline SZMC 22226 & 66 & Male & $\begin{array}{c}\text { Fungal } \\
\text { corneal ulcer }\end{array}$ & 2 March 2013 & $\begin{array}{l}\text { NAT, ECZ, } \\
\text { HTR } \\
\end{array}$ & $\begin{array}{l}\text { Lost to follow up } \\
\text { after one visit }\end{array}$ \\
\hline SZMC 26758 & 40 & Male & $\begin{array}{c}\text { Fungal } \\
\text { corneal ulcer }\end{array}$ & 21 March 2011 & $\begin{array}{l}\text { NAT, ECZ, } \\
\text { HTR }\end{array}$ & $\begin{array}{l}\text { Lost to follow up } \\
\text { after one visit }\end{array}$ \\
\hline SZMC 26759 & NA & NA & $\begin{array}{c}\text { Fungal } \\
\text { corneal ulcer }\end{array}$ & NA & NA & Lost to follow up \\
\hline
\end{tabular}

NAT: natamycin (5\%); ECZ: econazole (2\%), HTR: homatropine (1\%); NA: data not available.

\subsection{Updated Phylogeny of the Genus Curoularia}

Table 2 shows the strains and sequences involved in the phylogenetic analysis of the genus Curvularia, including four isolates derived from cases of fungal keratitis diagnosed and treated in the Aravind Eye Hospital, Coimbatore, Tamil Nadu, India. The tef1 $\alpha$ dataset consisted of 902 characters of nucleotide alignment without binary characters. The gpdh dataset contained 684 characters with 601 characters of nucleotide alignment and 63 binary characters derived from indel coding. The length of the ITS alignment was 1193 characters long, containing $896 \mathrm{bp}$ of nucleotide data and 297 binary characters.

Table 2. Sequences used for the phylogenetic analysis.

\begin{tabular}{|c|c|c|c|c|}
\hline \multirow{2}{*}{ Curvularia Species } & \multirow[t]{2}{*}{ Strain } & \multicolumn{3}{|c|}{ GenBank Accession Number } \\
\hline & & ITS & tef1a & gpdh \\
\hline Bipolaris maydis & CBS $136.29^{\mathrm{T}}$ & KJ909780 & KM093794 & KM034846 \\
\hline Curvularia aeria & BRIP $61232 b$ & KX139029 & KU552155 & KU552162 \\
\hline Curvularia affinis & CBS $154.34^{\mathrm{T}}$ & KJ909782 & KM196566 & KM230401 \\
\hline Curvularia ahvazensis & SCUA-1bi ${ }^{\mathrm{T}}$ & KJ415539 & MG428686 & MG428693 \\
\hline Curvularia akaii & CBS 317.86 & JX256420 & KM196569 & KM230402 \\
\hline Curvularia akaiiensis & BRIP $16080^{\mathrm{T}}$ & HE861833 & KJ415453 & KJ415407 \\
\hline Curvularia alcornii & MFLUCC $10-0703^{\mathrm{T}}$ & JX256424 & JX266589 & $\mathrm{JX} 276433$ \\
\hline Curvularia americana & UTHSC 08-3414 ${ }^{\mathrm{T}}$ & KJ415540 & - & HF565488 \\
\hline Curvularia asiatica & MFLUCC $10-0711^{\mathrm{T}}$ & KJ415541 & JX266593 & JX276436 \\
\hline Curvularia australiensis & BRIP $12044^{\mathrm{T}}$ & KJ415542 & KJ415452 & KJ415406 \\
\hline Curvularia australis & BRIP $12521^{\mathrm{T}}$ & MH414892 & KJ415451 & KJ415405 \\
\hline Curvularia bannonii & BRIP $16732^{\mathrm{T}}$ & MH414894 & KJ415450 & KJ415404 \\
\hline Curvularia beasleyi & BRIP $10972^{\mathrm{T}}$ & MH414911 & MH433654 & MH433638 \\
\hline Curvularia beerburrumensis & BRIP $12942^{\mathrm{T}}$ & KP400638 & MH433657 & MH433634 \\
\hline Curvularia boeremae & IMI $164633^{\mathrm{T}}$ & KJ415543 & - & MH433641 \\
\hline Curvularia borreriae & MFLUCC 11-0422 & KJ922372 & KM196571 & KP419987 \\
\hline Curvularia bothriochloae & BRIP $12522^{\mathrm{T}}$ & KJ909765 & KJ415449 & KJ415403 \\
\hline Curoularia brachyspora & CBS 186.50 & HG778984 & KM230405 & KM061784 \\
\hline Curvularia buchloës & CBS $246.49^{\mathrm{T}}$ & MF490814 & KM196588 & KM061789 \\
\hline Curvularia carica-papayae & CBS $135941^{\mathrm{T}}$ & HG779021 & - & HG779146 \\
\hline Curvularia chiangmaiensis & CPC $28829^{\mathrm{T}}$ & MH275055 & MF490857 & MF490836 \\
\hline Curoularia chlamydospora & UTHSC $07-2764^{\mathrm{T}}$ & KU552205 & - & HG779151 \\
\hline Curvularia chonburiensis & MFLUCC $16-0375^{\mathrm{T}}$ & MH414897 & - & MH412747 \\
\hline Curvularia clavata & BRIP 61680b & AF081447 & KU552159 & KU552167 \\
\hline Curvularia coatesiae & BRIP $24261^{\mathrm{T}}$ & MH414898 & MH433659 & MH433636 \\
\hline Curvularia coicis & CBS $192.29^{\mathrm{T}}$ & LT631357 & JN601006 & AF081410 \\
\hline Curvularia colbranii & BRIP $13066^{\mathrm{T}}$ & LT631310 & MH433660 & MH433642 \\
\hline
\end{tabular}


Table 2. Cont.

\begin{tabular}{|c|c|c|c|c|}
\hline \multirow{2}{*}{ Curvularia Species } & \multirow[t]{2}{*}{ Strain } & \multicolumn{3}{|c|}{ GenBank Accession Number } \\
\hline & & ITS & tef1a & gpdh \\
\hline Curvularia comoriensis & CBS 110673 & KJ415544 & - & LT715841 \\
\hline Curvularia crassiseptum & CBS $503.90^{\mathrm{T}}$ & HG778985 & - & LT715882 \\
\hline Curvularia crustacea & BRIP $13524^{\mathrm{T}}$ & MF490815 & KJ415448 & KJ415402 \\
\hline Curvularia cymbopogonis & CBS 419.78 & KJ415545 & - & HG779129 \\
\hline Curvularia dactyloctenicola & CPC $28810^{\mathrm{T}}$ & LT631356 & MF490858 & MF490837 \\
\hline Curvularia dactyloctenii & BRIP $12846^{\mathrm{T}}$ & JN192375 & KJ415447 & KJ415401 \\
\hline Curvularia deightonii & CBS 537.70 & MH414899 & - & LT715839 \\
\hline Curvularia ellisii & CBS $193.62^{\mathrm{T}}$ & HG778986 & JN601007 & JN600963 \\
\hline Curvularia eragrosticola & BRIP $12538^{\mathrm{T}}$ & KJ909781 & MH433661 & MH433643 \\
\hline Curvularia eragrostidis & CBS 189.48 & HG778987 & - & HG779154 \\
\hline Curvularia geniculata & CBS 187.50 & JN192376 & KM230410 & KM083609 \\
\hline Curvularia gladioli & CBS 210.79 & KJ415546 & - & HG779123 \\
\hline Curvularia graminicola & BRIP $23186 a^{\mathrm{T}}$ & KJ415547 & JN601008 & JN600964 \\
\hline Curvularia harveyi & BRIP $57412^{\mathrm{T}}$ & KJ415548 & KJ415446 & KJ415400 \\
\hline Curvularia hawaiiensis & BRIP $11987^{\mathrm{T}}$ & KJ415549 & KJ415445 & KJ415399 \\
\hline Curvularia heteropogonicola & BRIP $14579^{\mathrm{T}}$ & HG779011 & KJ415444 & KJ415398 \\
\hline Curvularia heteropogonis & CBS $284.91^{\mathrm{T}}$ & JN192380 & JN601013 & JN600969 \\
\hline Curvularia hominis & CBS $136985^{\mathrm{T}}$ & KJ922375 & - & HG779106 \\
\hline Curvularia homomorpha & CBS $156.60^{\mathrm{T}}$ & HG778991 & JN601014 & JN600970 \\
\hline Curoularia inaequalis & CBS $102.42^{\mathrm{T}}$ & MH861533 & KM196574 & KM061787 \\
\hline Curvularia intermedia & CBS 334.64 & MH414900 & - & HG779155 \\
\hline Curvularia ischaemi & CBS $630.82^{\mathrm{T}}$ & MH855025 & - & LT715790 \\
\hline Curvularia kenpeggii & BRIP $14530^{\mathrm{T}}$ & MH414901 & MH433662 & MH433644 \\
\hline Curvularia kusanoi & CBS 137.29 & JX256429 & JN601016 & LT715862 \\
\hline Curvularia lamingtonensis & BRIP $12259^{\mathrm{T}}$ & JF812154 & MH433663 & MH433645 \\
\hline Curvularia lunata & CBS $730.96^{\mathrm{T}}$ & MH414902 & JX266596 & JX276441 \\
\hline Curvularia malina & CBS $131274^{\mathrm{T}}$ & HE792934 & KR493095 & KP153179 \\
\hline Curvularia mebaldsii & BRIP $12900^{\mathrm{T}}$ & MF139088 & MH433664 & MH433647 \\
\hline Curvularia micropus & CBS 127235 & KJ909770 & - & LT715859 \\
\hline Curvularia microspora & GUCC $6272^{\mathrm{T}}$ & MG846737 & MF139115 & MF139106 \\
\hline Curvularia miyakei & CBS $197.29^{\mathrm{T}}$ & KP400647 & KM196568 & KM083611 \\
\hline Curvularia mosaddeghii & IRAN $3131 C^{\mathrm{T}}$ & KJ415550 & MH392152 & MH392155 \\
\hline Curvularia muehlenbeckiae & CBS $144.63^{\mathrm{T}}$ & MH414910 & KM196578 & KP419996 \\
\hline Curvularia neergaardii & BRIP $12919^{\mathrm{T}}$ & KJ415551 & KJ415443 & KJ415397 \\
\hline Curvularia neoindica & IMI $129790^{\mathrm{T}}$ & MF490816 & MH433667 & MH433649 \\
\hline Curvularia nicotiae & BRIP $11983^{\mathrm{T}}$ & JN601033 & KJ415442 & KJ415396 \\
\hline Curvularia nodosa & CPC $28800^{\mathrm{T}}$ & KP400650 & MF490859 & MF490838 \\
\hline Curvularia nodulosa & CBS 160.58 & JN192384 & JN601019 & JN600975 \\
\hline Curvularia oryzae & CBS $169.53^{\mathrm{T}}$ & KJ922380 & KM196590 & KР645344 \\
\hline Curvularia ovariicola & CBS $470.90^{\mathrm{T}}$ & MH275056 & JN601020 & JN600976 \\
\hline Curvularia pallescens & CBS $156.35^{\mathrm{T}}$ & KJ415552 & KM196570 & KM083606 \\
\hline Curvularia pandanicola & MFLUCC $15-0746^{\mathrm{T}}$ & HG778995 & MH412763 & MH412748 \\
\hline Curvularia papendorfii & CBS $308.67^{\mathrm{T}}$ & MH414905 & KJ415441 & KJ415395 \\
\hline Curvularia perotidis & CBS $350.90^{\mathrm{T}}$ & KY905678 & KM230407 & HG779138 \\
\hline Curvularia petersonii & BRIP $14642^{\mathrm{T}}$ & MH414906 & MH433668 & MH433650 \\
\hline Curvularia pisi & CBS $190.48^{\mathrm{T}}$ & KJ415553 & KY905697 & KY905690 \\
\hline Curvularia platzii & BRIP $27703 b^{T}$ & KJ922373 & MH433669 & MH433651 \\
\hline Curvularia portulacae & BRIP $14541^{\mathrm{T}}$ & KJ922376 & KJ415440 & KJ415393 \\
\hline Curvularia prasadii & CBS $143.64^{\mathrm{T}}$ & MF490819 & KM230408 & KM061785 \\
\hline Curoularia protuberata & CBS $376.65^{\mathrm{T}}$ & HE861842 & KM196576 & KM083605 \\
\hline Curvularia pseudobrachyspora & CРC $28808^{\mathrm{T}}$ & HE861838 & MF490862 & MF490841 \\
\hline
\end{tabular}


Table 2. Cont.

\begin{tabular}{|c|c|c|c|c|}
\hline \multirow{2}{*}{ Curvularia Species } & \multirow[t]{2}{*}{ Strain } & \multicolumn{3}{|c|}{ GenBank Accession Number } \\
\hline & & ITS & tef1a & gpdh \\
\hline Curvularia pseudolunata & UTHSC 09-2092 T & JN192386 & - & HF565459 \\
\hline Curvularia pseudorobusta & UTHSC 08-3458 & MH414907 & - & HF565476 \\
\hline Curvularia ravenelii & BRIP $13165^{\mathrm{T}}$ & KJ415555 & JN601024 & JN600978 \\
\hline Curvularia reesii & BRIP $4358^{\mathrm{T}}$ & KJ909783 & MH433670 & MH433637 \\
\hline Curvularia richardiae & BRIP $4371^{\mathrm{T}}$ & KX139030 & KJ415438 & KJ415391 \\
\hline Curvularia robusta & CBS $624.68^{\mathrm{T}}$ & KJ415556 & KM196577 & KM083613 \\
\hline Curoularia rouhanii & SCUA-2bi-2 ${ }^{\mathrm{T}}$ & HG779001 & MG428687 & MG428694 \\
\hline Curvularia ryleyi & BRIP $12554^{\mathrm{T}}$ & KY905679 & KJ415437 & KJ415390 \\
\hline Curvularia senegalensis & CBS 149.71 & KJ415558 & - & HG779128 \\
\hline Curvularia soli & CBS $222.96^{\mathrm{T}}$ & MH414904 & KY905698 & KY905691 \\
\hline Curvularia sorghina & BRIP $15900^{\mathrm{T}}$ & KP400655 & KJ415435 & KJ415388 \\
\hline Curvularia sp. & BRIP $17068 b$ & KР400654 & MH433666 & MH433648 \\
\hline Curvularia sp. & AR5117 & HE861826 & KP735698 & KР645349 \\
\hline Curvularia sp. & MFLUCC 120177 & JN192387 & KP735697 & KР645348 \\
\hline Curvularia sp. & UTHSC 8809 & MH414908 & - & HF565477 \\
\hline Curvularia spicifera & CBS 274.52 & KJ909777 & JN601023 & JN600979 \\
\hline Curvularia sporobolicola & BRIP $23040 b^{T}$ & MH275057 & MH433671 & MH433652 \\
\hline Curvularia subpapendorfii & CBS $656.74^{\mathrm{T}}$ & HG779023 & KM196585 & KM061791 \\
\hline Curvularia thailandicum & MFLUCC $15-0747^{\mathrm{T}}$ & JN192388 & MH412764 & MH412749 \\
\hline Curvularia trifolii & CBS 173.55 & KJ415559 & - & HG779124 \\
\hline Curvularia tripogonis & BRIP $12375^{\mathrm{T}}$ & КС424596 & JN601025 & JN600980 \\
\hline Curvularia tropicalis & BRIP $14834^{\mathrm{T}}$ & JX256433 & KJ415434 & KJ415387 \\
\hline Curvularia tsudae & ATCC $44764^{\mathrm{T}}$ & HG779024 & KC503940 & KC747745 \\
\hline Curvularia tuberculate & CBS $146.63^{\mathrm{T}}$ & MF490822 & JX266599 & JX276445 \\
\hline Curvularia uncinate & CBS $221.52^{\mathrm{T}}$ & HG779026 & - & HG779134 \\
\hline Curvularia variabilis & CPC $28815^{\mathrm{T}}$ & KP400652 & MF490865 & MF490844 \\
\hline Curvularia verruciformis & CBS 537.75 & MH414909 & - & HG779133 \\
\hline Curvularia verruculosa & CBS 150.63 & MH275058 & KP735695 & KР645346 \\
\hline Curvularia warraberensis & BRIP $14817^{\mathrm{T}}$ & AF071338 & MH433672 & MH433653 \\
\hline Curvularia xishuangbannaensis & KUMCC $17-0185^{\mathrm{T}}$ & KJ909780 & MH412765 & MH412750 \\
\hline Curvularia gudauskasii & DAOM 165085 & KX139029 & KM093794 & AF081393 \\
\hline \multirow[t]{3}{*}{ Curvularia tamilnaduensis sp. nov. } & SZMC $22226^{\mathrm{T} *}$ & MN628311 & MN628303 & MN628307 \\
\hline & SZMC $26758 *$ & MN628308 & MN628300 & MN628304 \\
\hline & SZMC $26759 *$ & MN628309 & MN628301 & MN628305 \\
\hline Curvularia coimbatorensis sp. nov. & SZMC $22225^{\mathrm{T} *}$ & MN628310 & MN628302 & MN628306 \\
\hline
\end{tabular}

On the phylograms obtained from each of the three loci, the four keratitis isolates of this study were resolved as two new species with over $80 \%$ of confidence values (data not shown), one of them represented by the single isolate SZMC 22225, while the other one by isolates SZMC 22226, SZMC 26758, and SZMC 26758. As the individual inferences were largely congruent, the three loci were concatenated and partitioned. The phylogenetic tree obtained from the concatenated dataset is shown in Figure 1. 


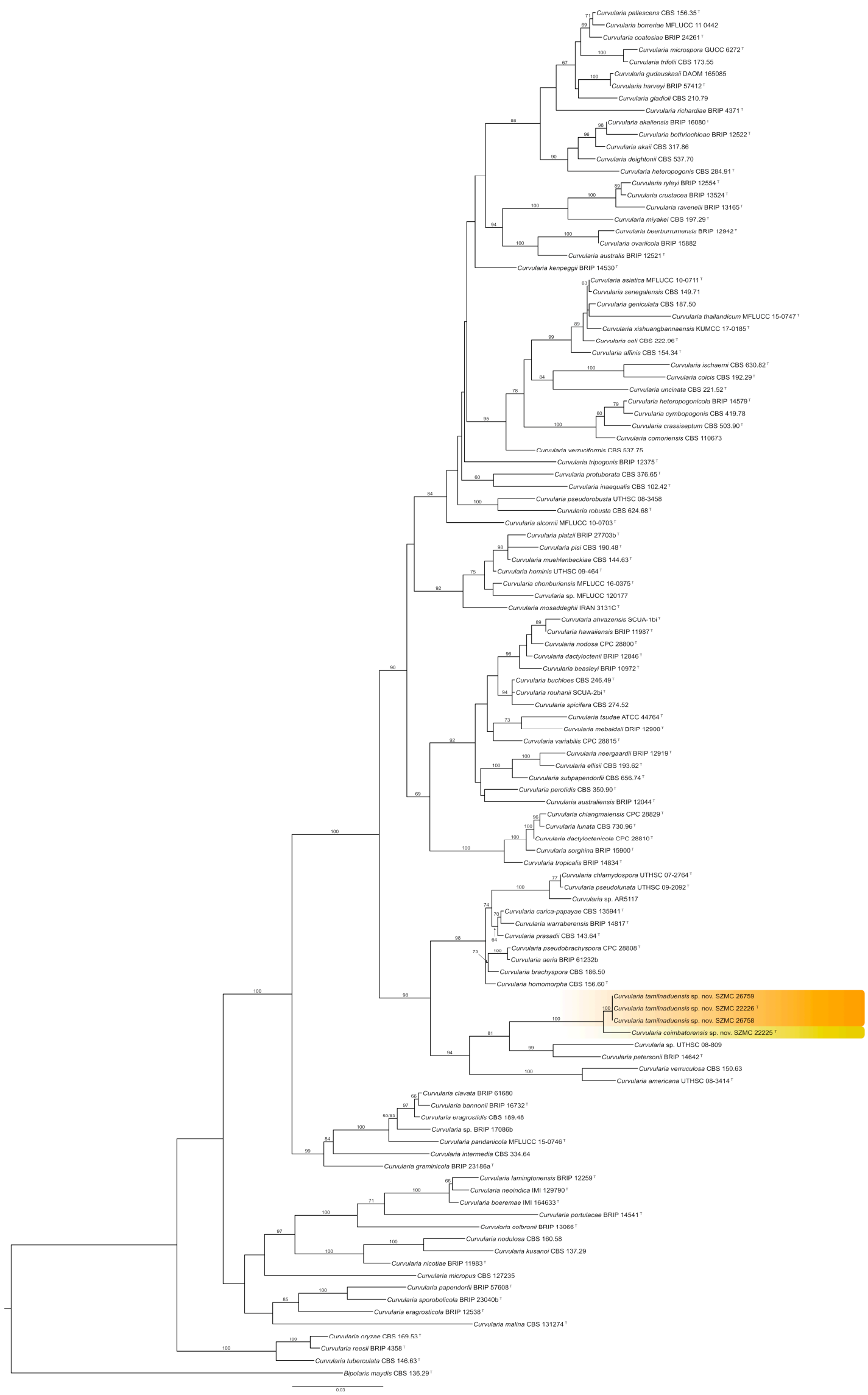

Figure 1. Maximum likelihood phylogeny of the genus Curvularia inferred from the concatenated internal transcribed spacer (ITS), translation elongation factor $1-\alpha$ (tef1a), and glyceraldehyde-3-phosphate dehydrogenase $(g p d h)$ sequences. The isolates examined in this study are 
shown as the new species Curvularia tamilnaduensis and Curvularia coimbatorensis (highlighted in color). Sequences of the reference Curvularia strains were collected from the GenBank Nucleotide database (Table 1). Bootstrap support values greater than $60 \%$ are shown above the branches. Bipolaris maydis CBS 136.29 was used to root the tree. Abbreviations of culture collections: BRIP: Plant Pathology Herbarium, Queensland, Australia; CBS: Westerdijk Fungal Biodiversity Institute culture collection, The Netherlands; CPC: Cultures of Pedro Crous, housed at Westerdijk Fungal Biodiversity Institute; DAOM: Canadian National Mycological Herbarium, Ottawa, Canada; GUCC: Guizhou University Culture Collection, Guizhou, China; IMI: CABI Bioscience, Eggham, UK; IRAN: Iranian Fungal Culture Collection, Iranian Research Institute of Plant Protection, Tehran, Iran; KUMCC: Culture Collection of Kunming Institute of Botany, Kunming, China; MFLUCC: Mae Fah Luang Culture Collection, Chiang Rai, Thailand; SCUA: Collection of Fungal Cultures, Department of Plant Protection, Shahid Chamran University of Ahvaz, Iran; SZMC: Szeged Microbiology Collection, Szeged, Hungary; UTHSC: University of Tennessee Health Science Center, Memphis, USA. T : type strain.

\subsection{Taxonomy and Related Information}

Curvularia coimbatorensis N. Kiss \& S. Kocsubé sp. nov. (Figure 2). MycoBank accession number: MB 833656. The etymology is referring to the city in Tamil Nadu, South India where the type strain was isolated.
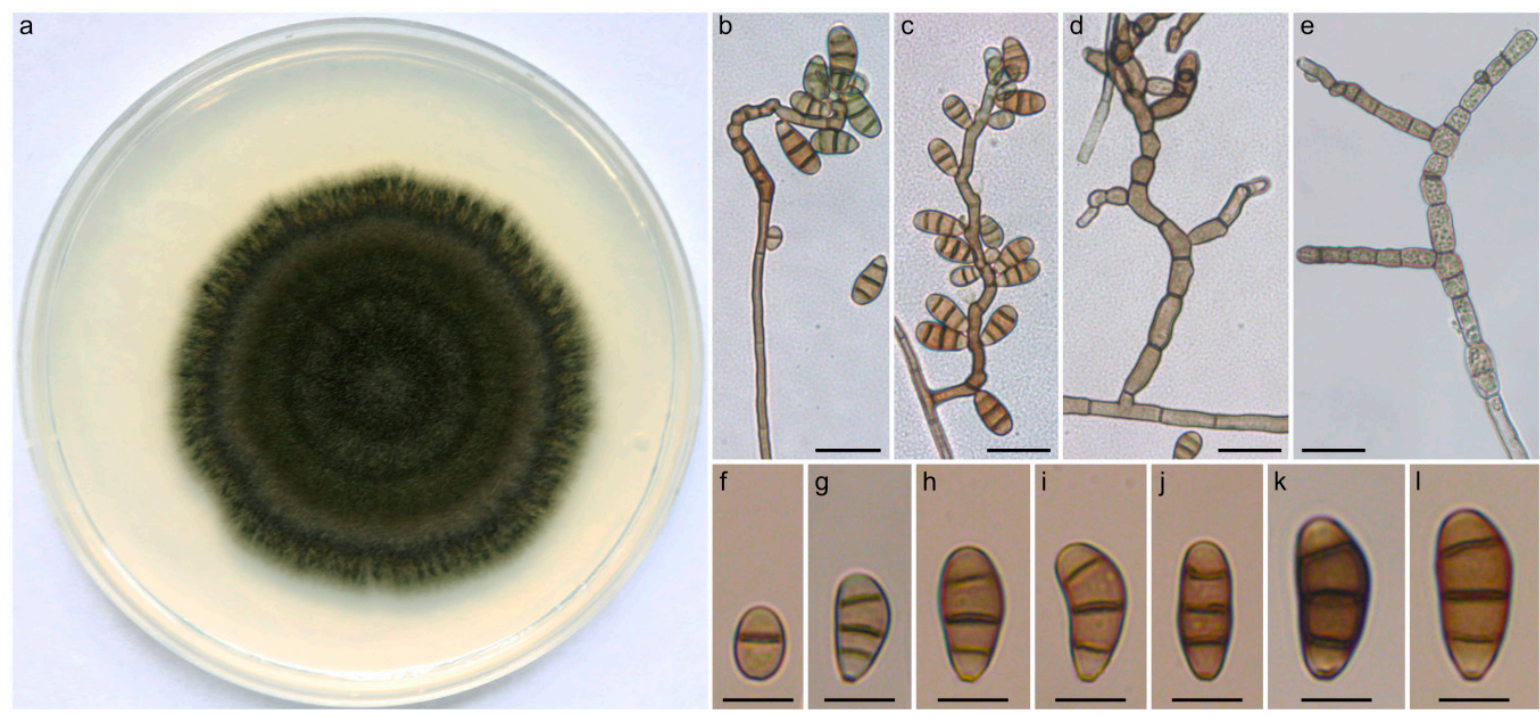

Figure 2. Morphological features of Curvularia coimbatorensis SZMC 2225. (a) Colony morphology on PDA (potato dextrose agar) medium after 7 days at $25^{\circ} \mathrm{C} ;(\mathbf{b}, \mathbf{c})$ conidiophores with septate conidia; (d) branching conidiophores; (e) swollen cells; (f-1) septate conidia. Scale bars: (b-e) $20 \mu \mathrm{m} ;(\mathbf{f}-\mathbf{l}) 10 \mu \mathrm{m}$.

Vegetative hyphae septate, subhyaline to brown, branched, smooth, $3-4 \mu \mathrm{m}$ in width. Colonies on PDA reaching approximately $4-6 \mathrm{~cm}$ in diameter after 7 days at $25^{\circ} \mathrm{C}$, surface funiculose, margin fimbriate, olivaceous black to olivaceous grey, velutinous with sparse aerial mycelium. Conidiophores erect, often branched, in most cases uniformly brown, sometimes pale brown at apex, seminematous, septate, flexuous, in most cases geniculate towards the apex, up to $210 \mu \mathrm{m}$ long, 3-4 $\mu \mathrm{m}$ wide, basal cells sometimes swollen. Conidiogenous cells integrated, terminal, or intercalary with sympodial proliferation, smooth, brown, mono- or polytretic. Chlamydospores not observed. Conidia ellipsoidal to clavate to obovoid, asymmetrical with paler end cells, usually curved at the third cell from the base, (13-)16-18(-23) × (7-)8-9(-10) $\mu \mathrm{m}, 3$-distoseptate, hila slightly protuberant, thickened and darkened.

Specimens examined: India, Coimbatore, human corneal scraping from corneal ulcer, 2012, (holotype: freeze dried culture specimen in the Szeged Microbiological Collection (SZMC) at the 
Department of Microbiology, Faculty of Science and Informatics, University of Szeged, Hungary, SZMC 22225, includes ex-type culture).

Curvularia tamilnaduensis N. Kiss \& S. Kocsubé sp. nov. (Figure 3). MycoBank accession number: MB 833657. The etymology is referring to the state of South India where the type strain and the other two examined strains were isolated.
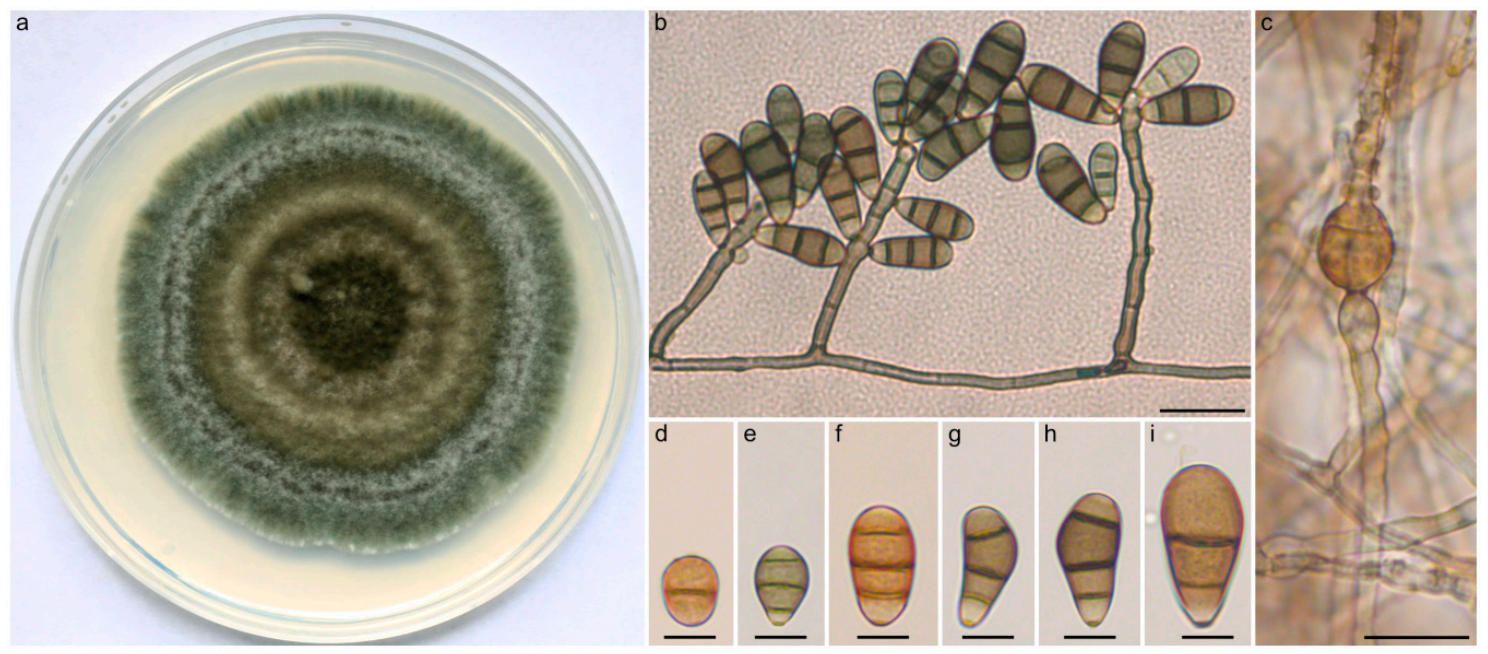

Figure 3. Morphological features of Curvularia tamilnaduensis SZMC 2226. (a) Colony morphology on PDA medium after 7 days at $25^{\circ} \mathrm{C}$; (b) conidiophores with septate conidia; (c) subglobose intercalary chlamydospore; (d-f) septate conidia. Scale bars: $(\mathbf{b}, \mathbf{c}) 20 \mu \mathrm{m} ;(\mathbf{d}-\mathbf{i}) 10 \mu \mathrm{m}$.

Vegetative hyphae septate, subhyaline to brown, branched, smooth walled, but often heavily asperulate, 2-3 $\mathrm{mm}$ in width. Colonies on PDA reaching approximately 6-7 $\mathrm{cm}$ in diameter after 7 days at $25{ }^{\circ} \mathrm{C}$, surface lanose, aerial mycelium abundant, margin fimbriate, olivaceous green. Conidiophores erect, usually unbranched, in most cases uniformly brown, sometimes with paler tip, seminematous, septate, slightly flexuous, rarely geniculate towards the apex, up to $125 \mu \mathrm{m}$ long, 2.5-4 $\mu \mathrm{m}$ wide. Conidiogenous cells integrated, terminal or intercalary, smooth, pale brown to brown, mono- or polytretic, proliferating sympodially. Chlamydospores present, subglobose, terminal and intercalary, 8-22 $\mu \mathrm{m}$ in diameter. Conidia ellipsoidal to clavate to obovoid, asymmetrical with paler basal and apical cells, usually curved at the third cell from the base which is darker than the other cells, (15-)20-23(-28) $\times(7-) 8-10(-11) \mu \mathrm{m},(2-) 3-d i s t o s e p t a t e$ with non-protuberant, thickened, and darkened hila.

Specimens examined: India, Coimbatore, human corneal scraping from corneal ulcer, 2013, (holotype: freeze dried culture specimen in the Szeged Microbiological Collection (SZMC) at the Department of Microbiology, Faculty of Science and Informatics, University of Szeged, Hungary, SZMC 22226, includes ex-type culture); India, Coimbatore, human corneal scraping from corneal ulcer, 2011, (SZMC 26758); India, Coimbatore, human corneal scraping from corneal ulcer, 2011-2013, (SZMC 26759).

\subsection{Antifungal Susceptibilities of Curvularia Strains Isolated from Fungal Keratitis}

The minimum inhibitory concentrations (MIC) of nine antifungal agents towards C. coimbatorensis SZMC 22225, C. tamilnaduensis SZMC 22226, SZMC 26758, and SZMC 26759, as well as the type strains of C. australiensis (CBS 172.57), C. hawaiiensis (CBS 173.57), and C. spicifera (CBS 274.52) are shown in Table 3. The MIC of natamycin was $2 \mu \mathrm{g} \mathrm{mL} \mathrm{m}^{-1}$ for both new species and all other strains tested, while substantial differences between them could be observed in the case of clotrimazole, econazole, miconazole, and terbinafine, with the type strain of $C$. coimbatorensis having 4, 8, 4, and 4-8 times higher values, respectively. Among the tested isolates, the type strain of $C$. spicifera proved to be the less susceptible to clotrimazole, econazole, fluconazole, ketoconazole, and miconazole. Notable 
strain-to-strain variations between the C. tamilnaduensis strains could be observed only in the case of itraconazole and ketoconazole with detected MIC ranges of $0.03-0.25$ and $0.06-0.25$, respectively.

Table 3. Antifungal susceptibilities of the Curvularia coimbatorensis and Curvularia tamilnaduensis strains in comparison with the type strains of Curvularia australiensis, Curvularia hawaiiensis, and Curvularia spicifera determined by the CLSI (Clinical \& Laboratory Standards Institute) broth microdilution method (minimum inhibitory concentrations (MIC) values in $\mu \mathrm{g} \mathrm{mL}^{-1}$ ).

\begin{tabular}{|c|c|c|c|c|c|c|c|c|c|}
\hline \multirow{2}{*}{ Strain } & \multicolumn{9}{|c|}{ Antifungal Agent } \\
\hline & AMB & CLT & ECN & FLC & ITC & KTC & MCZ & NTM & TRB \\
\hline C. australiensis CBS $172.57^{\mathrm{T}}$ & 0.25 & 0.25 & 0.125 & 16 & 0.03 & 0.25 & 0.25 & 2 & 0.25 \\
\hline C. hawaiiensis CBS $173.57^{\mathrm{T}}$ & 0.25 & 0.06 & 0.06 & 4 & 0.03 & 0.06 & 0.125 & 2 & 0.25 \\
\hline C. spicifera CBS $274.52^{\mathrm{T}}$ & 0.5 & 4 & 2 & $>32$ & 0.25 & 2 & 2 & 2 & 1 \\
\hline C. coimbatorensis SZMC $22225^{\mathrm{T}}$ & 0.5 & 0.5 & 1 & 32 & 0.25 & 0.25 & 1 & 2 & 1 \\
\hline C. tamilnaduensis SZMC $22226^{\mathrm{T}}$ & 1 & 0.125 & 0.125 & 8 & 0.03 & 0.06 & 0.25 & 2 & 0.25 \\
\hline C. tamilnaduensis SZMC 26758 & 0.5 & 0.125 & 0.125 & 16 & 0.03 & 0.25 & 0.25 & 2 & 0.125 \\
\hline C. tamilnaduensis SZMC 26759 & 1 & 0.125 & 0.125 & 16 & 0.25 & 0.25 & 0.25 & 2 & 0.25 \\
\hline
\end{tabular}

${ }^{\mathrm{T}}$ : type strain; AMB: amphotericin B; CLT: clotrimazole; ECN: econazole; FLC: fluconazole; ITC: itraconazole; KTC: ketoconazole; MCZ: miconazole; NTM: natamycin; TRB: terbinafine.

\section{Discussion}

The phylogenetic tree obtained from the concatenated dataset of three loci presents an update about the phylogeny of Curvularia, which is mostly in agreement with the recently published phylogenies of this genus (Figure 1). C. ischaemi formed a clade with C. coicis, which is in contradiction with the results of Tan et al. [8] and Tibpromma et al. [27], where C. ischaemi formed a sister clade to C. gladioli, but in agreement with the phylogram obtained by Madrid et al. [7] and Manamgoda et al. [28]. Our analysis placed C. perotidis as a sister clade to $C$. australiensis, however, other studies $[7,8,27,29]$ suggested that this species is closer to $C$. spicifera. The placement of $C$. variabilis was also different from previously published articles [8,29]. According to the analyses of Tan et al. [8] and Marin-Felix et al. [29], C. variabilis forms a clade with C. hawaiiensis, C. nodosa, C. dactyloctenicola, and C. beasleyi, however, in this study we found $C$. variabilis as a sister clade of $C$. tsudae and C. mebaldsii. The same authors found C. tripogonis, C. pseudorobusta, C. robusta, C. alcornii, C. protuberata, and C. inaequalis as members of two distinct monophyletic clades, while our results indicate that these species are closely related and paraphyletic, however, none of the topologies have strong statistical supports. The observed slight differences between the previous inferences and our analyses did not affect the validity of any of the previously described species, and some of them might be the result of the slightly broader taxon sampling.

One of the newly described species, C. coimbatorensis is only known from the type specimen isolated from corneal ulcer. Phylogenetic analysis based on three loci placed C. coimbatorensis as a sister clade to the other newly described species $C$. tamilnaduensis. The two species are closely related, but can be distinguished by tef1a, gpdh, and ITS sequences, with percentage identities of $99 \%, 98 \%$, and $99 \%$, respectively. C. petersonii [8] is also closely related and can be distinguished by all three loci $(98 \%$ in tef 1 a, $93 \%$ in gpdh and $96 \%$ in ITS). C. coimbatorensis differs from C. tamilnaduensis in colony morphology, the lack of chlamydospores, and the size of conidia. C. petersonii is very similar in colony morphology, however, has significantly shorter (up to $110 \mu \mathrm{m}$ ) and only slightly geniculate conidiophores bearing narrower (5-)5.5-6(-7) conidia [8]. C. coimbatorensis has longer conidiophores.

The phylogenetic analysis based on three loci placed the other newly described species, C. tamilnaduensis as a sister clade to the recently described species C. petersonii. C. tamilnaduensis can be reliably distinguished from the ex-type of C. petersonii by tef1a, gpdh and ITS sequences with percentage identities of $99 \%, 95 \%$, and $96 \%$, respectively. The two species also differ by morphology, as C. petersonii has not been reported to produce chlamydospores and has different conidial dimensions (17-19 × 5.5-6) [8]. C. americana [7] and C. verruculosa [30] are also related species with considerable amount of genetic distances and none of these species have been reported before to have chlamydopores. 
C. americana has $4(-5)$-distoseptate and wider $(7-15 \mu \mathrm{m})$ conidia, while $C$. verruculosa has mostly 3-distoseptate conidia, but also wider $(12-17 \mu \mathrm{m})$ than those of $C$. tamilnaduensis.

The antifungal susceptibilities of the examined strains of $C$. coimbatorensis and $C$. tamilnaduensis to amphotericin B, clotrimazole, econazole, fluconazole, itraconazole, ketoconazole, miconazole, natamycin, and terbinafine were within the MIC ranges reported for other clinically relevant Curvularia species in the study of Guarro et al. [11] and the review of Krizsán et al. [3]. The type strain of C. coimbatorensis proved to be less susceptible than the strains of $C$. tamilnaduensis to all antifungals except for natamycin. For itraconazole and ketoconazole our results are in agreement with the study of Guarro et al. [11], who reported that amphotericin B, itraconazole, miconazole and ketoconazole are highly effective against a series of Curvularia species known from fungal keratitis (C. brachyspora, C. clavata, C. geniculata, C. lunata, C. pallescens, C. senegalensis, and C. verruculosa).

\section{Materials and Methods}

\subsection{Curvularia Strains, Culture Conditions, and Morphological Examination}

The Curvularia strains involved in this study derived from corneal scrapings from fungal corneal ulcers of keratitis patients attending the Aravind Eye Hospital and Postgraduate Institute of Ophthalmology, Coimbatore, India. All cases were initially screened by experienced ophthalmologists, and the corneal scrapings were collected following the clinical diagnosis of fungal keratitis. The samples were initially processed microbiologically for the isolation of the causative agents as described earlier [31]. The corneal scrapings of all patients were subjected to Gram stain, Giemsa stain, and 10\% $\mathrm{KOH}$ wet mount. Culture methods involved direct inoculation of specimens onto $5 \%$ sheep blood agar, chocolate agar, non-nutrient agar, potato dextrose agar, thioglycolate broth, and brain-heart infusion broth. The microbial cultures were considered positive only if the growth of the same organism was demonstrated on two or more solid media, or there was confluent growth at the site of inoculation on one solid medium with consistent direct microscopic findings. The isolates were deposited in the Szeged Microbiology Collection (SZMC, Szeged, Hungary) under the accession numbers SZMC 22225, SZMC 22226, SZMC 26758, and SZMC 26759. Colony morphology of the isolates was examined on PDA (BioLab, Budapest, Hungary) medium after 7 days of incubation at $25{ }^{\circ} \mathrm{C}$ under normal day/night light conditions. Micromorphological characters were examined with a Leica DMI 4000B (Leica, Wetzlar, Germany) microscope equipped with a Leica DFC 295 camera. Microscopic features were examined in lactic acid $(100 \% v / v)$ on glass slides. Conidiophores were studied in the same mounting fluid with the transparent tape method. Conidiophores and conidia were measured using the software ImageJ v2.52a (National Institute of Mental Health, Bethesda, MD, USA). Size ranges of the conidia were derived from 50 measurements. Lengths and widths are given as (minimum value) mean size minus SD-mean size plus SD (maximum value).

\subsection{DNA Extraction, Amplification, Sequencing, and Phylogenetic Analysis}

Genomic DNA was isolated from the examined Curoularia strains SZMC 22225, SZMC 22226, SZMC 26758, and SZMC 26759 with the Masterpure ${ }^{\mathrm{TM}}$ Yeast DNA Purification Kit (Epicentre Biotechnologies, Madison, WI, USA) according to the manufacturer's instructions. Fragments of tef $1 a$ and $g p d h$ were amplified as described previously $[5,32,33]$. The ITS region of the ribosomal RNA gene cluster was amplified according to White et al. [34]. Sequencing of the amplicons was carried out on a 3500 Genetic Analyzer (Thermo Fisher Scientific, Waltham, MA, USA) by the sequencing service of the Biological Research Centre, Szeged, Hungary. Resulting sequences were deposited in the GenBank Nucleotide database (www.ncbi.nlm.nih.gov) under the accession numbers shown in Table 2.

Sequences of the four clinical isolates were aligned with publicly available sequences of 108 previously described Curvularia species, as well as Bipolaris maydis as the outgroup (Table 2). Phylogenetic analyses were conducted using three loci (tef1 $\alpha, g p d h$ and ITS). Sequences of all three loci were aligned with the phylogeny-aware sequence alignment tool Canopy v0.1.4 using RAxML as tree 
estimator and PRANK [35] with the -F option as the aligner with 10 iterations and seed decomposition strategy. Alignments of the three loci were concatenated and partitioned by region. The tef1 $\alpha$ sequences formed one partition while in the case of gpdh sequences the dataset was partitioned to exons and introns. The ITS dataset was divided to rDNA and ITS1-ITS2 regions. Alignments of $g p d h$ and ITS datasets contained high number of indels with important phylogenetic signal, therefore gaps were coded as absence/presence characters by SequenceMatrix v1.8 [36] using the simple indel coding algorithm [37]. The two indel matrices were concatenated and added as a single partition to the dataset. Maximum likelihood analysis was performed using RAxML-NG v0.9.0 [38] under the GTR model with gamma-distributed rate heterogeneity using empirical base frequencies. As indel-based datasets do not contain constant sites, the ascertainment bias correction described by Lewis [39] was used for this partition. Statistical support of the best ML tree was obtained with 1000 thorough bootstrap replicates.

\subsection{Antifungal Susceptibility Testing}

In vitro antifungal susceptibility tests were carried out according to the CLSI M38-A2 broth microdilution method [40]. Nine antifungal agents: amphotericin B, clotrimazole, econazole, fluconazole, itraconazole, ketoconazole, miconazole, natamycin and terbinafine (Sigma-Aldrich, Budapest, Hungary) were examined. Microtiter plates were incubated at $35^{\circ} \mathrm{C}$ for $72 \mathrm{~h}$. Plates were evaluated both spectrophotometrically with a Spectrostar Nano microplate reader (BMG Labtech, Ortenberg, Germany) and by visual examination.

\section{Conclusions}

The present study demonstrates, that although the phylogeny of the genus Curvularia is resolved and well established, further expansion can be expected both in the list of described Curvularia species and in the known spectrum of clinically relevant members of the genus. The collection of further keratitis isolates from the genus Curvularia and gaining data about their antifungal susceptibilities are therefore tasks of increasing importance. Furthermore, comparing the infectivity of various Curvularia species causing keratitis-including the recently described ones-in animal keratitis models would be an intriguing topic for future research.

Author Contributions: Conceptualization, S.K., L.K., T.P. and C.V.; methodology, N.K., A.M., M.H. and S.K.; software, S.K.; validation, R.R., P.M., M.H., C.V., M.V. and S.K.; formal analysis, K.K., T.P. and M.V.; investigation, N.K., A.M., P.M., K.K., M.H., M.V. and S.K.; resources, R.R., P.M., A.M., T.P. and C.V.; data curation, N.K., S.K., K.K., L.K. and M.H.; writing-original draft preparation, N.K., S.K., L.K.; writing-review and editing, N.K., S.K., L.K., P.M., T.P. and C.V.; visualization, N.K., M.H. and S.K.; supervision, S.K.; project administration, S.K., T.P., L.K., and P.M.; funding acquisition, S.K., T.P., L.K. and P.M. All authors have read and agreed to the published version of the manuscript.

Funding: This research was funded by grants NKFI PD-116609 (National Research, Development and Innovation Office, Hungary), GINOP-2.3.2-15-2016-00035 (Széchenyi 2020 Programme) and also supported by the COST action HUPLANTcontrol (Control of Human Pathogenic Micro-organisms in Plant Production Systems, CA16110). LK is grantee of the János Bolyai Research Scholarship (Hungarian Academy of Sciences) and the Bolyai Plus Scholarship (New National Excellence Programme). TP and MH are supported by the grants LP2016-8/2016 and by the FIKP program (TUDFO/4738-1/2019 ITM) of the Ministry of Human Capacities.

Acknowledgments: The authors wish to thank Venkatapathy Narendran (Aravind Eye Hospital and Postgraduate Institute of Ophthalmology, Coimbatore, Tamil Nadu, India), Coimbatore Subramanian Shobana (Department of Microbiology, PSG College of Arts and Science, Coimbatore, Tamil Nadu, India) and Kanesan Panneer Selvam (Department of Microbiology, M.R Government Arts College, Mannargudi, Tamil Nadu, India) for constantly supporting the research efforts on fungal keratitis within the frames of the Indo-Hungarian Fungal Keratitis Research Group.

Conflicts of Interest: The authors declare no conflict of interest. 


\section{References}

1. Bengyella, L.; Iftikhar, S.; Nawaz, K.; Fonmboh, D.J.; Yekwa, E.L.; Jones, R.C.; Njanu, Y.M.T.; Roy, P. Biotechnological application of endophytic filamentous Bipolaris and Curvularia: A review on bioeconomy impact. World J. Microbiol. Biotechnol. 2019, 35, 69. [CrossRef] [PubMed]

2. Kusai, N.A.; Azmi, M.M.Z.; Zulkifly, S.; Yusof, M.T.; Zainudin, N.A.I.M. Morphological and molecular characterization of Curvularia and related species associated with leaf spot disease of rice in Peninsular Malaysia. Rend. Lincei Sci. Fis. Nat. 2016, 27, 205-214. [CrossRef]

3. Krizsán, K.; Papp, T.; Manikandan, P.; Shobana, C.S.; Chandrasekaran, M.; Vágvölgyi, C.; Kredics, L. Clinical Importance of the Genus Curvularia. In Medical Mycology: Current Trends and Future Prospects; Razzaghi-Abyaneh, M., Shams-Ghahfarokhi, M., Rai, M., Eds.; CRC Press: Boca Raton, FL, USA, 2016; pp. 147-204. [CrossRef]

4. Yanagihara, M.; Kawasaki, M.; Ishizaki, H.; Anzaw, K.; Udagawa, S.; Mochizuki, T.; Sato, Y.; Tachikawa, N.; Hanakawa, H. Tiny keratotic brown lesions on the interdigital web between the toes of a healthy man caused by Curvularia species infection and a review of cutaneous Curvularia infections. Mycoscience 2010, 51, 224-233. [CrossRef]

5. Manamgoda, D.S.; Cai, L.; McKenzie, E.H.C.; Crous, P.W.; Madrid, H.; Chukeatirote, E.; Shivas, R.G.; Tan, Y.P.; Hyde, K.D. A phylogenetic and taxonomic re-evaluation of the Bipolaris-Cochliobolus-Curvularia complex. Fungal Divers. 2012, 56, 131-144. [CrossRef]

6. Paredes, K.; Capilla, J.; Sutton, D.A.; Mayayo, E.; Fothergill, A.W.; Guarro, J. Virulence of Curvularia in a murine model. Mycoses 2013, 56, 512-515. [CrossRef] [PubMed]

7. Madrid, H.; da Cunha, K.C.; Gené, J.; Dijksterhuis, J.; Cano, J.; Sutton, D.A.; Guarro, J.; Crous, P.W. Novel Curvularia species from clinical specimens. Persoonia 2014, 33, 48-60. [CrossRef] [PubMed]

8. Tan, Y.P.; Crous, P.W.; Shivas, R.G. Cryptic species of Curvularia in the culture collection of the Queensland Plant Pathology Herbarium. MycoKeys 2018, 35, 1-25. [CrossRef] [PubMed]

9. Marcus, L.; Vismer, H.F.; van der Hoven, H.J.; Gove, E.; Meewes, P. Mycotic keratitis caused by Curvularia brachyspora (Boedjin). A report of the first case. Mycopathologia 1992, 119, 29-33. [CrossRef] [PubMed]

10. Travis, W.D.; Kwon-Chung, K.J.; Kleiner, D.E.; Geber, A.; Lawson, W.; Pass, H.I.; Henderson, D. Unusual aspects of allergic bronchopulmonary fungal disease: Report of two cases due to Curvularia organisms associated with allergic fungal sinusitis. Hum. Pathol. 1991, 22, 1240-1248. [CrossRef]

11. Guarro, J.; Akiti, T.; Horta, R.A.; Morizot Leite-Filho, L.A.; Gené, J.; Ferreira-Gomes, S.; Aguilar, C.; Ortoneda, M. Mycotic keratitis due to Curvularia senegalensis and in vitro antifungal susceptibilities of Curvularia spp. J. Clin. Microbiol. 1999, 37, 4170-4173. [PubMed]

12. Fan, Y.M.; Huang, W.M.; Li, S.F.; Wu, G.F.; Li, W.; Chen, R.Y. Cutaneous phaeohyphomycosis of foot caused by Curvularia clavata. Mycoses 2009, 52, 544-546. [CrossRef] [PubMed]

13. Vasikasin, V.; Nasomsong, W.; Srisuttiyakorn, C.; Mitthamsiri, W.; Oer-Areemitr, N.; Changpradub, D. Disseminated phaeohyphomycosis caused by Curvularia tuberculata in a previously healthy man. Mycopathologia 2019, 184, 321-325. [CrossRef]

14. Pimentel, J.D.; Mahadevan, K.; Woodgyer, A.; Sigler, L.; Gibas, C.; Harris, O.C.; Lupino, M.; Athan, E. Peritonitis due to Curvularia inaequalis in an elderly patient undergoing peritoneal dialysis and a review of six cases of peritonitis associated with other Curvularia spp. J. Clin. Microbiol. 2005, 43, 4288-4292. [CrossRef] [PubMed]

15. Posteraro, B.; Scarano, E.; La Sorda, M.; Torelli, R.; De Corso, E.; Mulé, A.; Paludetti, G.; Fadda, G.; Sanguinetti, M. Eosinophilic fungal rhinosinusitis due to the unusual pathogen Curvularia inaequalis. Mycoses 2010, 53, 84-88. [CrossRef]

16. Cruz, R.; Barthel, E.; Espinoza, J. Allergic rhinosinusitis by Curvularia inaequalis (Shear) Boedijn. Rev. Chil. Infectol. 2013, 30, 319-322. (In Spanish) [CrossRef] [PubMed]

17. Flanagan, K.L.; Bryceson, A.D. Disseminated infection due to Bipolaris australiensis in a young immunocompetent man: Case report and review. Clin. Infect. Dis. 1997, 25, 311-313. [CrossRef] [PubMed]

18. Filizzola, M.J.; Martinez, F.; Rauf, S.J. Phaeohyphomycosis of the central nervous system in immunocompetent hosts: Report of a case and review of the literature. Int. J. Infect. Dis. 2003, 7, 282-286. [CrossRef] 
19. Gadgil, N.; Kupferman, M.; Smitherman, S.; Fuller, G.N.; Rao, G. Curvularia brain abscess. J. Clin. Neurosci. 2013, 20, 173-175. [CrossRef]

20. Vachharajani, T.J.; Zaman, F.; Latif, S.; Penn, R.; Abreo, K.D. Curvularia geniculata fungal peritonitis: A case report with review of literature. Int. Urol. Nephrol. 2005, 37, 781-784. [CrossRef]

21. Diskin, C.J.; Stokes, T.J.; Dansby, L.M.; Radcliff, L.; Carter, T.B. Case report and review: Is the tendency for Curvularia tubular obstruction significant in pathogenesis? Perit. Dial. Int. 2008, 28, 678-679.

22. Saenz, R.E.; Brown, W.D.; Sanders, C.V. Allergic bronchopulmonary disease caused by Bipolaris hawaiiensis presenting as a necrotizing pneumonia: Case report and review of literature. Am. J. Med. Sci. 2001, 321, 209-212. [CrossRef] [PubMed]

23. Robson, A.M.; Craver, R.D. Curvularia urinary tract infection: A case report. Pediatr. Nephrol. 1994, 8, 83-84. [CrossRef] [PubMed]

24. Safdar, A. Curvularia-Favorable response to oral itraconazole therapy in two patients with locally invasive phaeohyphomycosis. Clin. Microbiol. Infect. 2003, 9, 1219-1223. [CrossRef] [PubMed]

25. Fernandez, M.; Noyola, D.E.; Rossmann, S.N.; Edwards, M.S. Cutaneous phaeohyphomycosis caused by Curvularia lunata and a review of Curvularia infections in pediatrics. Pediatr. Infect. Dis. J. 1999, 18, 727-731. [CrossRef] [PubMed]

26. Dave, V.P.; Joseph, J.; Pathengay, A.; Pappuru, R.R.; Das, T. Clinical presentations, diagnosis, and management outcomes of Curvularia endophthalmitis and a review of literature. Retina 2018. [CrossRef] [PubMed]

27. Tibpromma, S.; Hyde, K.D.; Bhat, J.D.; Mortimer, P.E.; Xu, J.; Promputtha, I.; Doilom, M.; Yang, J.B.; Tang, A.M.C.; Karunarathna, S.C. Identification of endophytic fungi from leaves of Pandanaceae based on their morphotypes and DNA sequence data from southern Thailand. MycoKeys 2018, 33, 25-67. [CrossRef] [PubMed]

28. Manamgoda, D.S.; Rossman, A.Y.; Castlebury, L.A.; Crous, P.W.; Madrid, H.; Chukeatirote, E.; Hyde, K.D. The genus Bipolaris. Stud. Mycol. 2014, 79, 221-288. [CrossRef]

29. Marin-Felix, Y.; Senwanna, C.; Cheewangkoon, R.; Crous, P.W. New species and records of Bipolaris and Curvularia from Thailand. Mycosphere 2017, 8, 1556-1574. [CrossRef]

30. Sivanesan, A. Graminicolous species of Bipolaris, Curvularia, Drechslera, Exserohilum and their teleomorphs. Mycol. Pap. 1987, 158, 1-261.

31. Mythili, A.; Babu Singh, Y.R.; Priya, R.; Shafeeq Hassan, A.; Manikandan, P.; Panneerselvam, K.; Narendran, V.; Shobana, C.S. In vitro and comparative study on the extracellular enzyme activity of molds isolated from keratomycosis and soil. Int. J. Ophthalmol. 2014, 7, 778-784. [CrossRef]

32. Schoch, C.L.; Crous, P.W.; Groenewald, J.Z.; Boehm, E.W.A.; Burgess, T.I.; de Gruyter, J.; de Hoog, G.S.; Dixon, L.J.; Grube, M.; Gueidan, C.; et al. A class-wide phylogenetic assessment of Dothideomycetes. Stud. Mycol. 2009, 64, 1-15. [CrossRef] [PubMed]

33. Berbee, M.; Pirseyedi, M.; Hubbard, S. Cochliobolus phylogenetics and the origin of known, highly virulent pathogens, inferred from ITS and glyceraldehyde-3-phosphate dehydrogenase gene sequences. Mycologia 1999, 91, 964-977. [CrossRef]

34. White, T.J.; Bruns, T.D.; Lee, S.; Taylor, J.W. Amplification and direct sequencing of fungal ribosomal genes for phylogenetics. In PCR Protocols: A Guide to Methods and Applications; Innis, M.A., Gelfand, D.H., Sninsky, J.J., White, J.W., Eds.; Academic Press: San Diego, CA, USA, 1990; pp. 315-322.

35. Löytynoja, A. Phylogeny-aware alignment with PRANK. Meth. Mol. Biol. 2014, 1079, 155-170. [CrossRef]

36. Vaidya, G.; Lohman, D.J.; Meier, R. SequenceMatrix: Concatenation software for the fast assembly of multigene datasets with character set and codon information. Cladistics 2011, 27, 171-180. [CrossRef]

37. Simmons, M.P.; Ochoterena, H. Gaps as characters in sequence-based phylogenetic analysis. Syst. Biol. 2000, 49, 369-381. [CrossRef]

38. Kozlov, A.M.; Darriba, D.; Flouri, T.; Morel, B.; Stamatakis, A. RAxML-NG: A fast, scalable, and user-friendly tool for maximum likelihood phylogenetic inference. Bioinformatics 2019, 35, 4453-4455. [CrossRef] 
39. Lewis, P.O. A likelihood approach to estimating phylogeny from discrete morphological character data. Syst. Biol. 2001, 50, 913-925. [CrossRef]

40. Clinical and Laboratory Standards Institute. Reference Method for Broth Dilution Antifungal Susceptibility Testing of Yeasts, 3rd ed.; Approved Standard, CLSI Document M27-A3; Clinical and Laboratory Standards Institute: Wayne, PA, USA, 2008.

(C) 2019 by the authors. Licensee MDPI, Basel, Switzerland. This article is an open access article distributed under the terms and conditions of the Creative Commons Attribution (CC BY) license (http://creativecommons.org/licenses/by/4.0/). 